\title{
Die Art, wie einer stirbt. Eine Henkerswahrheit
}

Im Andenken an Clairette Karakash, am 9. Juli 2002 tödlich verunglückt

\section{Pierre Bühler}

Der Mann, ein Schriftsteller, sitzt im Dunkeln an seinem Schreibtisch. Der andere klettert durch das Fenster ins Zimmer hinein, und zerbricht dabei, ungeschickt, einen griechischen Weinkrug. So beginnt das Hörspiel »Nächtliches Gespräch mit einem verachteten Menschen« von Friedrich Dürrenmatt ${ }^{1}$.

\section{»Verächtlichster unter den Menschen «}

"Der Mann" und "der andere«: Zwischen diesen zwei Gestalten, oder besser - da es ja ein Hörspiel ist - zwischen diesen zwei Stimmen entwickelt sich ein nächtliches Zwiegespräch. Der Mann wartete auf Besuch, er ahnte, dass jemand kommen musste, um ihn umzubringen, denn er war der Regierung gegenüber in Missgunst geraten. "Der Ministerpräsident hat mich angegriffen, man weiss, was dies bedeutet, die Reden Seiner Exzellenz pflegen unästhetische Folgen zu haben." (S. 14) Gefangen im Gefängnis der Ächtung des Staates, verlassen von den Freunden (»da sich jeder zum Tode verurteilt, der mich besucht «, S. 15), war er sich darauf gefasst, dass man einmal einen Menschen zu ihm schicken würde, um ihm den Tod zu geben. Erwartet hatte er jedoch einen Mörder, und für diesen hatte er bereits eine grosse Rede vorbereitet. Einen Mörder hätte er würdig empfangen, mit ihm wie mit einem Bruder ge-kämpft, um ihn in der Triumphstunde seines Todes mit seinem Geist zu besiegen. "Diesem Menschen wollte ich noch einmal - zum letztenmal - sagen, wofür ich ein ganzes Leben lang gekämpft habe. Ich wollte ihm zeigen, was die Freiheit ist, ich wollte ihm beweisen, dass ein freier Mann nicht zittert.« (S. 15)

Doch nun ist nicht ein Mörder gekommen, sondern der Henker, der seit fünfzig Jahren für den Staat Menschen umbringt. "Es freut mich, dass der Staat wenigstens einen Fachmann schickt und keinen

\footnotetext{
${ }^{1}$ Geschrieben 1951, erstmals 1952 in einer Zeitschrift, 1957 dann in Buchform veröffentlicht. Der Untertitel heisst: »Ein Kurs für Zeitgenossen«. Das Stück wurde im Laufe der Jahrzehnte mehrmals als Theaterstück aufgeführt, als Radiohörspiel gesendet und als Fernsehfilm produziert. Ich zitiere den Text nach der Werkausgabe in 37 Bänden, Zürich, Diogenes, 1998, Bd. 17, 9-32.
} 
Anfänger.« (S. 16) Aber trotzdem ist die Enttäuschung gross: Was könnte man schon einem Henker Erhabenes sagen? Der Henker, "ein Beamter..., der tötet und einmal fürs Töten eine Pension beziehen wird, um satt wie eine Spinne auf seinem Sofa einzuschlafen«, ist »verächtlichster unter den Menschen« (ebd.).

\section{Kunst des Sterbens}

Diesem "verachteten Menschen" gegenüber vergeht dem Schriftsteller zunächst das Sprechen. Doch gerade dadurch kann er nun auch auf ihn hören. Denn der Henker hat durchaus etwas zu sagen. Zugegeben, er versteht zwar nichts von der Freiheit, für die heute alle kämpfen, und dasselbe gilt von der Gerechtigkeit (vgl. S. 17). Den rasenden Lauf der Welt, das Aufsteigen und Versinken der Menschen, ihre Kämpfe und Niederlagen, all das erahnt er nur bruchstückhaft. Bei ihm bleibt alles gleich, »das immer gleiche $\mathrm{Zu}-$ schlagen, bei Schuldigen und Unschuldigen, zuschlagen, zuschlagen wie ein Hammer, zuschlagen wie ein Beil, das man nicht fragt« (S. 18). Doch das langjährige Henken hat den Henker nicht gleichgültig gemacht. Auf die etwas gehässige Frage des Schriftstellers »Was ist einem Henker schon wichtig?", antwortet er: "Die Art, wie einer stirbt, Herr." (Ebd.) Er habe, so der Henker, gewaltige Unterschiede bei der "Kunst des Sterbens" beobachtet. Er sehe, dass einige diese Kunst besitzen und viele nicht. Es gebe "Stümper in dieser Kunst" und "grosse Meister" (S. 19). Um es wirklich zu erfassen, müsste er zwar mehr von den Menschen wissen, "wie sie in ihrem Leben sind, was sie denn eigentlich unternehmen die ganze ungeheure Zeit über, bis sie zu mir kommen; was das heisst, heiraten, Kinder haben, Geschäfte machen, eine Ehre besitzen, eine Maschine handhaben, spielen und trinken, einen Pflug führen, Politik betreiben, sich für Ideen oder ein Vaterland aufopfern, nach Macht streben, und was man nur immer tut« (ebd.). Deshalb wisse er auch nicht die ganze Wahrheit vom Menschen, sondern nur seine Wahrheit.

Also eine perspektivische Wahrheit, die Wahrheit über das Sterben des Menschen aus der Perspektive des Henkers. Und so sagt ihm denn auch der Schriftsteller mit kritischem Ton: "Zeig sie her, deine Henkerswahrheit.« (Ebd.) 


\section{Drei Arten des Sterbens}

Der Henker unterscheidet zunächst drei Arten des Sterbens. Davon ausgehend, dass das Leben alles sei, was man beim Sterben verlieren könne, habe er zunächst natürlich gefunden, dass man sich gegen den Henker wehre, dass sich ein Kampf mit ihm entwickle. "So starben die wilden Burschen aus den Wäldern, die im Jähzorn töteten oder einen Raubmord unternahmen, um ihrem Mädchen einen roten Rock zu kaufen. ... Da war Verbrechen in ihrem Handeln und Gerechtigkeit in meinem Henken, die Rechnung war klar und ging auf. Sie starben einen gesunden Tod.» (S. 20)

Bei der zweiten Art des Sterbens verschiebt sich die Perspektive. Zwar wird der Henker weiterhin verachtend behandelt, jedoch im stolzen Gefühl, im Recht zu sein. Grosse Reden über Freiheit und Gerechtigkeit werden hier gehalten, die Reichen oder die Tyrannen angegriffen, um damit $\mathrm{zu}$ zeigen, wie gleichgültig der Tod gegenüber der Sache des geführten Kampfes ist. "Auch hier war die Rechnung klar und einfach: Es war Krieg zwischen ihnen und mir. Sie starben im Zorn und in der Verachtung, und ich schlug im Zorn $\mathrm{zu}$, die Gerechtigkeit lag bei beiden, meine ich. Die starben einen imposanten Tod." (S. 21)

Dieses heldenhafte Sterben findet gleich den Beifall des Schriftstellers: "Brav umgekommen! Mögen heute viele so sterben!" (Ebd.) Doch der Henker weiss anderes zu berichten: $\mathrm{Zu}$ einem solchen Sterben bedarf es eines Publikums, wie früher bei den öffentlichen Hinrichtungen. "Aber heute hat sich das geändert. Man stirbt allein mit mir." Und damit kommt es zu einer dritten Art des Sterbens: »Da man mich verachtet, spricht man auch nicht mehr, und das Sterben stimmt dann auch nicht, weil die Rechnung nicht aufgeht und der Verurteilte zu kurz kommt. So sterben sie denn, wie Tiere sterben, gleichgültig, und das ist doch auch nicht die rechte Kunst... Das ist dann ein trauriger Tod.«(S. 21f.)

Der Schriftsteller scheint nun plötzlich resigniert: Er wollte wie ein Held sterben (im Sinne des imposanten Todes also), und nun ist er mit dem Henker allein. "Auch mir bleibt nichts anderes übrig, als umzukommen, wie die Tiere umkommen" - ein trauriger Tod also (S. 22). 


\section{Noch ein anderes Sterben...}

Doch hier bricht plötzlich eine Wende ins Gespräch ein, mit der knappen Bemerkung des Henkers, es gebe noch ein anderes Sterben. Der Schriftsteller horcht auf. Was denn diese vierte Art des Sterbens sei, fragt er. "Indem man demütig stirbt, Herr." (Ebd.) Diese Antwort löst zunächst den Zorn des Schriftstellers aus. Demut sei heute eine unanständige Tugend geworden, und man dürfe überhaupt nicht demütig sterben. Diese heftige Reaktion wird nun dazu führen, dass sich zwischen Henker und Schriftsteller die drei soeben beschriebenen Arten des Sterbens sukzessive abspielen, wie drei Phasen einer lebhaften Auseinandersetzung.

Wenn schon der Staat die Gerechten zwinge, wie Verbrecher zu sterben, wolle er auch wie ein Verbrecher mit dem Henker kämpfen. Gelassen antwortet der Henker: "Es ist sinnlos, mit mir zu kämpfen." (S. 23) Doch der Schriftsteller tritt zum Fenster und schreit in die Nacht hinein: "Hört, ihr Leute, hier kämpft einer mit seinem Henker! Hier wird einer wie ein Tier abgeschlachtet! Leute, springt aus euren Betten! Kommt und seht, in welchem Staat wir heute leben!« (Ebd.) Doch niemand bewegt sich, alles bleibt still. "Man stirbt heute allein. Die Furcht ist zu gross."(S. 24) Der Schriftsteller greift neben den Zigaretten nun zum Schnaps, und weil der Henker weiterhin gelassen bleibt, speit er dem verachteten Menschen Schnaps ins Gesicht. "Sie sind verzweifelt«, sagt der Henker (S. 25). Es folgt jetzt der Versuch des Schriftstellers, seinen Kampf mit den Waffen des Geistes zu rechtfertigen. Doch er bricht ab, denn der Henker ist nicht aus der Ruhe zu bringen. Und nach einer stillen Zeit kommt die dritte Phase, die des traurigen Todes:

- " "Ich kann nicht mehr kämpfen.»

- "Das müssen Sie auch nicht.»

- $\quad$ Ich bin müde.»

- "Das wird jeder einmal, Herr. (Ebd.)《

Etwas später heisst es dann: "Ich habe mich dir ergeben." (S. 26) Doch geschickt lenkt der Henker das Gespräch auf die vierte Art des Sterbens um: "Wie die Demütigen, Herr.« (Ebd.) Weil der Kampf durchgekämpft wurde, kann der Schriftsteller nun dem Henker zuhören. Nichts sei so schwer zu verstehen wie die Demütigen, aber wenn es einem gelinge, könne man erkennen, "dass sie die grossen 
Meister des Sterbens sind« (ebd.). Sie ergeben sich wie die Traurigen, aber nicht aus Müdigkeit. Zuerst habe er gedacht, es sei die Angst, doch wie die Stolzen hätten auch die Demütigen keine Angst. Deshalb habe er dann gedacht, es seien wohl die Verbrecher, die ihren Tod als Strafe hinnehmen. Aber merkwürdig sei, dass auch Unschuldige demütig sterben, und die seien am schwierigsten hinzurichten, da ihr Tod so irrsinnig und unbegreiflich sei. Heftig tut der Schriftsteller ein solches Sterben als Narrheit ab. Doch der Henker antwortet bloss: "Ich kann Ihnen nur sagen, was ich von denen gelernt habe, die unschuldig starben und demütig, Herr.«(S. 27) Der Schriftsteller bemerkt spöttisch: »Ei! Du lernst auch noch von den Unschuldigen, die du tötest! Das nenne ich praktisch!« (Ebd.) Der Henker lässt sich nicht aus der Ruhe bringen. Was er gelernt habe: "Was ich besiegen kann und was unbesiegbar ist.« Höhnisch fragt der Schriftsteller zurück: »Deine Macht findet ein Ende?« (Ebd.)

\section{Was besiegbar und was unbesiegbar ist}

Es folgt eine grosse Rede des Henkers. Seine Macht sei die Macht, die die Mächtigen auf ihn übertragen hätten, und damit sei auch die Schande auf ihn abgewälzt, "damit ich ihrer aller Schande trage" (S. 28). So könne man die Mächtigen bewundern, beneiden, so dass alle wie im Rausch nach Brocken der Macht schnappen, während der Henker allein, der verachtete Mensch, die Schande trägt.

Doch an ihm wird auch die Grenze der Macht offenbar. "Ihren Leib kann ich nehmen, Herr, der ist der Gewalt verfallen, denn alles, was in Staub zerfällt, ist ihr unterworfen, aber wofür Sie gekämpft haben, darüber habe ich keine Macht, denn es gehört nicht dem Staub." (S. 29) ${ }^{2}$ Damit verbindet sich die "Lehre« des demütigen Sterbens:

"Dass einer in der Stunde seines ungerechten Todes den Stolz und die Angst, ja auch sein Recht ablegt, um zu sterben, wie Kinder sterben, ohne die Welt zu verfluchen, ist ein Sieg, der grösser ist, als je ein Sieg eines Mächtigen war. Am leisen Hinsinken der Demütigen, an ihrem Frieden, der auch mich umschloss wie ein Gebet, an der Ungeheuerlichkeit ihres Sterbens, das jeder Vernunft widersprach, an diesen Dingen, die nichts sind vor der Welt als ein Gelächter, weniger noch, ein Achselzucken, offenbarte sich die Ohnmacht der Ungerechtigkeit, das Wesenlose des Todes und die Wirklichkeit des

\footnotetext{
${ }^{2}$ Diese Stelle enthält biblische Anspielungen, Gen 3,19 und Mt 10,28.
} 
Wahren, über die ich nichts vermag, die kein Scherge ergreift und kein Gefängnis umschliesst, von der ich nichts weiss, als dass sie ist. ..." (Ebd.)

Wenn der Mensch bloss Leib wäre, wäre es für die Mächtigen leicht, sie könnten ihre Reiche »Quader an Quader gefügt zu einer Welt aus Stein« erbauen (S. 30). Doch gilt hier, wie die Demütigen zeigen, etwas Unbesiegbares:

"... in die Leiber der Geschändeten, mit denen sie bauen, in dieses schwache Material ist das Wissen eingesenkt, wie die Welt sein soll, und die Erkenntnis, wie sie ist, die Erinnerung, wozu Gott den Menschen schuf, und der Glaube, dass diese Welt zerbrechen muss, damit sein Reich komme, als eine Sprengkraft, mächtiger denn jene der Atome, die den Menschen immer wieder umprägt, ein Sauerteig in seiner trägen Masse, der immer wieder die Zwingburgen der Gewalt sprengt, wie das sanfte Wasser die Felsen auseinanderzwängt und ihre Macht zu Sand zermahlt, der in einer Kinderhand zerrinnt." (ebd.)

Diese grossen Überlegungen werden vom Schriftsteller als Binsenwahrheiten abgetan. Worauf der Henker: „Es geht heute nur um Binsenwahrheiten, Herr.« (Ebd.)

\section{Der Henker als Offenbarer}

Nach einer Stille geht es nun aber dem Ende zu. Der Schriftsteller hat seine letzte Zigarette zu Ende geraucht. Auch Schnaps will er nicht mehr. Das Fenster wird geschlossen. Die erste Strassenbahn fährt, der Morgen bricht an.

Der Henker hat wie ein Offenbarer gewirkt. "Ich wollte zu meinem Mörder erhabene Dinge sprechen, nun hat der Henker zu mir einfache Dinge gesprochen." (S. 31) Bescheiden berichtet der Schriftsteller noch einmal, wie versöhnt, über seinen Kampf für Freiheit, Gerechtigkeit, Würde. "Es war ein Kampf um Selbstverständlichkeiten, und es ist eine traurige Zeit, in der man um das Selbstverständliche kämpfen muss." (Ebd.) Dieser Kampf, dieser gute Kampf wird aber weitergefuhrt werden. Immer wieder wird er aufgenommen, irgendwo, von irgendwem und zu jeder Stunde. Deshalb darf man ihn beim Eintreten des Todes auch loslassen. "... dann darf man wieder demütig sein, dann geht es um etwas, das nicht selbstverständlich ist: um die Vergebung unserer Sünden und um den Frieden unserer Seelen." (Ebd.) 
Und so ergibt sich denn am Schluss »der Mann« dem »anderen«:

- " "Ich habe nichts mehr zu sagen. Es ist soweit. Nimm jetzt das Messer.»

- "Sind Sie wohl in meinem Arm, Herr?»

- »Sehr wohl. Stoss zu. (S. 32)«

\section{Einfaches und Unselbstverständliches}

Das Hörspiel von Dürrenmatt verarbeitet auf originelle Weise die alte Tradition des "ars moriendi", in dem auch immer ein wars vivendi« auf dem Spiel steht. "Die Art, wie einer stirbt", offenbart auch die Art, wie einer lebt. Dürrenmatts Verarbeitung geschieht, wie der Untertitel andeutet, in Form eines "Kurses für Zeitgenossen". Das gibt dem Hörspiel teilweise einen etwas didaktischen Ton. Es steht jedoch fest: "Das Sterben ist eine gar zu schwere Kunst" (S. 25), und der Henker, mit seiner Henkerswahrheit, weiss auch nicht, "ob man diese Kunst lehren kann, noch wie man sie lernt" (S. 19). Ob es also eine Kunst des Sterbens, eine mars moriendi« gibt, und gar in Form eines Kurses, bleibt schliesslich offen. Sicher aber ist, dass es hier um "einfache Dinge " geht, die auch ein Henker, "verächtlichster unter den Menschen", sprechen kann, und dass in diesen einfachen Henkersdingen zugleich auch immer das Unselbstverständliche in Leben und Sterben anbricht.

Wie auch beim anderen "Verächtlichsten unter den Menschen", auf dessen Kommen wir im Dunkeln warten...

— Dr. Pierre Bühler ist Professor für Systematische Theologie an der Theologischen Fakultät. 